\title{
Uncertainties in the determination of the 'cortisol- binding capacity' of plasma and their removal
}

\author{
C. W. BURKE \\ From the Department of Medicine, Royal Postgraduate Medical School, Ducane Road, London
}

SYNOPSIS The determination of the 'cortisol-binding capacity' by gel filtration of a small plasma sample at low temperature after the addition of cortisol results in an arbitrary measurement dependent upon experimental conditions. It is unsatisfactory also because it misleads as to conditions at $37^{\circ} \mathrm{C}$. Steady-state gel filtration of cortisol in plasma can be done at $37^{\circ} \mathrm{C}$, at which temperature it overcomes known variables in present methods. It should prove of clinical value in showing abnormalities of cortisol binding in disease.

Only that fraction of the cortisol in plasma is biologically active which is not bound to protein (Slaunwhite, Lockie, Back, and Sandberg, 1962; Matsui and Plager, 1966). Most of the plasma cortisol circulates bound to corticosteroid-binding globulin. Measurement of the concentration of corticosteroid-binding globulin is thus of great interest. Many published figures for 'cortisol binding capacity' in health and disease have been obtained by the method of De Moor, Heirwegh, Heremans, and Declerck-Raskin (1962), or its modifications (Seal and Doe, 1963; Doe, Fernandez, and Seal, 1964). Evidence is presented below that these observations are arbitrary and misleading, and an alternative approach is suggested.

In the method of De Moor et al (1962) $500 \mathrm{ng}$ of cortisol is added to $1 \mathrm{ml}$ of plasma, which is then subjected to gel filtration at room temperature. The amount of cortisol in the protein fractions emerging from the column is measured, and when expressed in $\mu \mathrm{g} / 100 \mathrm{ml}$ of plasma is termed the "cortisol-binding capacity'. This term is rather misleading, for it disguises the complete disruption of the complex between cortisol and plasma albumin caused by the procedure (De Moor et al, 1962; Doe et al, 1964). Moreover, extensive dissociation of the complex between cortisol and corticosteroid-binding globulin also occurs in gel filtration at $37^{\circ} \mathrm{C}$ (Quincey and Gray, 1963; Burke, 1969) so that gel filtration has to be carried out at lower temperatures. De Moor et al (1962) believed the dissociation of the cortisolcorticosteroid-binding globulin complex to be 'unimportant' at room temperature, but it can be

Received for publication 13 February 1969. shown to be extensive when the elution profile is followed more closely.

If dissociation did not occur, two separate and symmetrical cortisol peaks should emerge from the column, one associated with protein and the other representing unbound cortisol in the original sample. Dissociation is revealed by departures from this ideal elution profile. For example, gel filtration of a small sample of an albumin-cortisol mixture yields only one cortisol peak which is unassociated with protein. So early and complete is the dissociation that the albumin-bound cortisol behaves as if unbound, irrespective of temperature (De Moor et al, 1962; Doe et al, 1964; Burke, 1969). I present evidence below that extensive dissociation of the cortisolcorticosteroid-binding globulin complex also occurs under the conditions of the method of De Moor et al (1962) for measuring cortisol-binding capacity. This is shown by collecting smaller fractions and measuring their cortisol content by a sensitive technique. Other defects in the method are also shown.

\section{METHODS}

Columns, $30 \times 1.4 \mathrm{~cm}$, of Sephadex G-50 were used. The eluant was $0 \cdot 15 \mathrm{M}$ sodium phosphate, $p \mathrm{H} \mathrm{7.4}$. The serum pool used was derived from a large number of cross-matching samples, many from ill patients. Its total cortisol concentration $(21.3 \mu \mathrm{g} / 100 \mathrm{ml})$ was determined in duplicate by dichloromethane extraction and paper chromatography with an internal isotopic standard in the Bush B5 system. The purified cortisol zone was eluted and measured by sulphuric-acid-induced fluorescence. (The limit of precision of this method was $\pm 12 \%$, mean \pm $5.7 \%$.) 
To the serum pool were added $500 \mathrm{ng} / \mathrm{ml}$ of pure cortisol and approximately $10^{5} \mathrm{dpm} / \mathrm{ml}$ of $1,2-{ }^{3} \mathrm{H}$-cortisol tracer (TRK 133, Radiochemical Centre). Samples of the serum with added cortisol were then passed through the columns, the conditions being indicated below, and the effluent was collected in $1 \mathrm{ml}$ fractions. The cortisol concentrations of these were determined from their measured radioactivity and the known specific activity of the cortisol in the sample. The elution rate was $0.5 \mathrm{ml} / \mathrm{min}$, shown in preliminary experiments to be well below that affecting results. Protein was measured by the method of Lowry, Rosebrough, Farr, and Randall (1951).

\section{EXPERIMENTAL FINDINGS AND INTERPRETATION}

METHOD OF DE MOOR et al (1962) Samples of the serum, each of $1 \mathrm{ml}$, with added cortisol were processed exactly according to the method of De Moor et al. The elution profile found in such an experiment is shown in Figure 1a. Much cortisol is present in the shaded area between the two principal cortisol peaks, and the cortisol peak not associated with protein is skewed. This second peak contains cortisol both originally unbound and originally bound to albumin, the reasons being indicated above. The shaded area contains cortisol which emerged earlier because it dissociated from complex with corticosteroid- binding globulin at various levels in the column. It is not due to chromatographic artefact, as I have $\stackrel{5}{\rightarrow}$ shown elsewhere (Burke, 1969). The amount of 0 cortisol in the shaded area is nearly as great as the 들 amount of cortisol remaining in the protein zone. $\frac{\bar{s}}{\bar{D}}$ Although the boundaries of the shaded area are $\stackrel{\mathbb{Q}}{\Omega}$ arbitrarily drawn as mirror images of the other halves of the peaks, its extent does suggest very extensive dissociation of cortisol-corticosteroid-. binding globulin complex on the column. This effect $\overrightarrow{\vec{\omega}}$ is significant also at $4^{\circ} \mathrm{C}$ (Burke, 1969).

The addition of the extraneous cortisol (called 'overloading' by De Moor et al (1962)) does not i simplify interpretation of the profile. The added cortisol will be removed by molecular sieving as $\sigma$ s soon as the sample begins to move down the column. This implies that the unbound cortisol in contact 을 with the proteins on the column is of the same order of magnitude as it would be if extra cortisol were $z$ not added. This is illustrated by studying the unbound cortisol concentration in contact with the proteins $\frac{\mathbb{S}}{3}$ near the column outlet; this cortisol emerges $\underset{\mathbb{Q}}{ }$ immediately after the proteins (Fig. 1, solid arrows). Its concentration was $5 \mathrm{ng} / \mathrm{ml}$ using added cortisol\& as in the method of De Moor et al (1962) (Fig. 1a), while it was $2 \mathrm{ng} / \mathrm{ml}$ in a similar experiment without

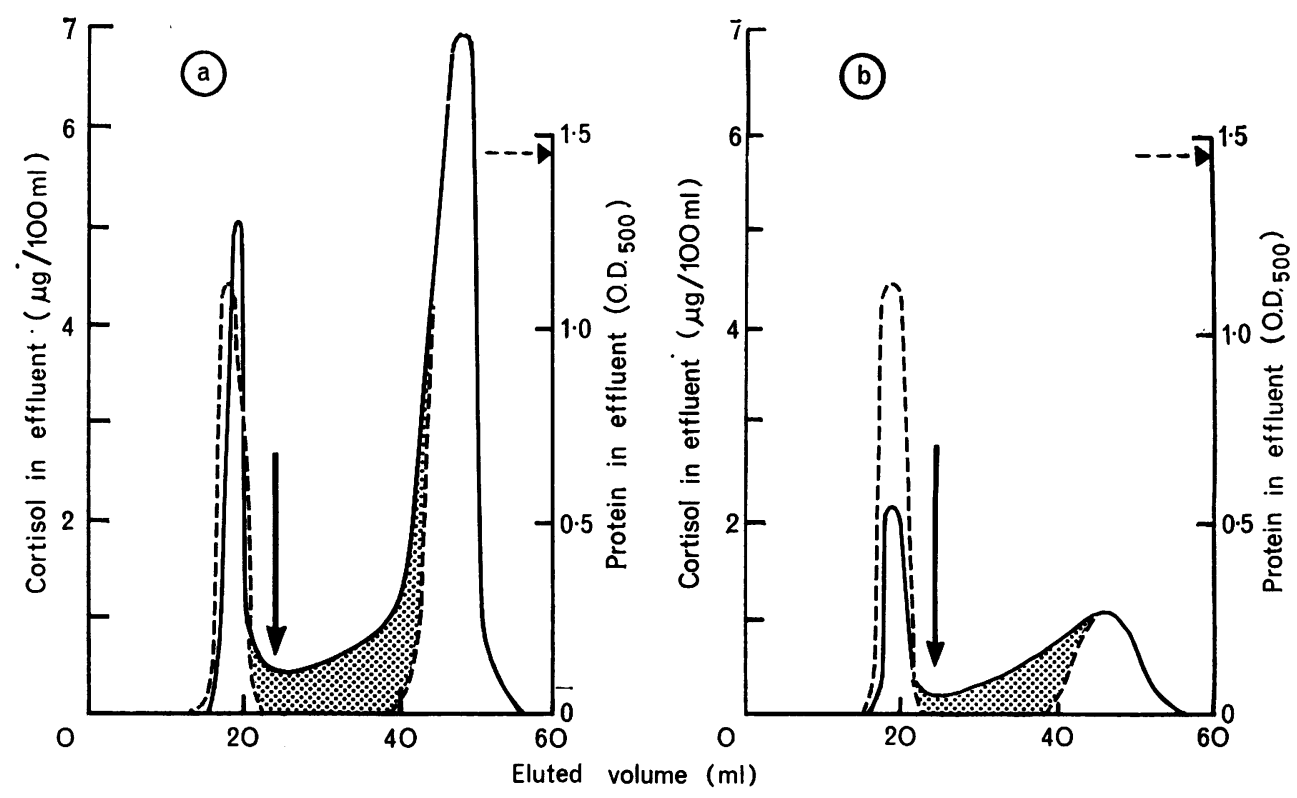

FIG. 1. Gel filtration of a $1 \mathrm{ml}$ serum sample: (a) with added cortisol under conditions of De Moor et al (1962); (b) conditions identical except extra cortisol not added. , cortisol in eluate, - - - , protein in eluate. Solid arrows and shading explained in text. 
added cortisol (Fig. 1b). Thus the actual effect of the addition of so much cortisol was to increase the unbound cortisol concentration on the column only two-and-a-half times, although it would be expected to increase it in the sample of normal serum thirtyfold or more. Therefore we may expect the effect of the added cortisol in suppressing dissociation to be slight. Although the shaded area is only an approximation to the amount of dissociated cortisol, its extent is not less with added cortisol (Fig. 1a) than it is without (Fig. 1b). This suggests the effect of the added cortisol to be very much less than expected, and it is, moreover, indefinite.

A further complication is the dilution of such small samples on the column. The original plasma protein concentration (shown by the arrow against the protein scale in Fig. 1) is not maintained during the gel filtration, due to zone spreading. This dilution, which favours dissociation, is a variable which depends upon both column performance and sample size.

Moreover, sample size has also a direct effect upon the dissociation; the smaller the sample the greater the relative dissociation on a given column (Burke, 1969). This is because the leading edge of the sample is the most subject to dissociation, and the smaller the sample the greater the fraction of it which may be considered as leading edge. The very significant effect of this variable upon the apparent "cortisolbinding capacity' is shown in Figure 2.

Another disadvantage of the method is its use of low temperatures. Results obtained at $23^{\circ} \mathrm{C}$ or $4^{\circ} \mathrm{C}$ cannot be extrapolated to conditions in vivo, for the marked change in binding affinity with temperature shown by steroid-binding proteins, including corticosteroid-binding globulin, is not identical for all steroids or all proteins (Sandberg, Rosenthal, Schneider, and Slaunwhite, 1966). For example, when applied to steroid competition for binding at room temperature (De Moor et al, 1962; De Moor, Deckx, and Steeno, 1963; De Moor and Steeno, 1965), the method gives a fallacious impression of the probable steroid competition for plasma proteins in vivo.

The combination of all these defects makes the determination of cortisol-binding capacity by $\mathrm{De}$ Moor's method highly arbitrary.

IMPROVED GEL FILTRATION METHOD These disadvantages can be avoided by relatively simple modifications of technique. I have shown elsewhere that steady-state gel filtration (Burke, 1969) enables cortisol binding to plasma protein to be measured at true equilibrium at body temperature in intact plasma; I show here how the method is also applicable to plasma at artificially elevated cortisol concentrations.

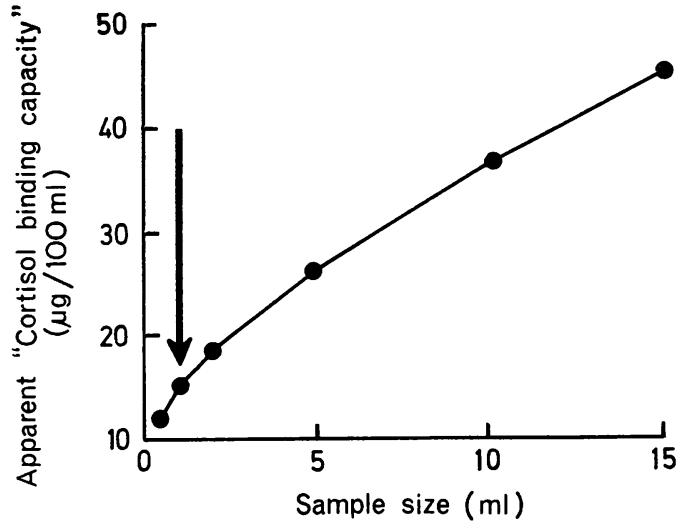

FIG. 2. Effect of sample size upon apparent 'cortisolbinding capacity' in method of De Moor et al (1962). Vertical arrow denotes sample size used in their method.

As an example, $42 \mathrm{ml}$ of the serum (with added cortisol) used in the experiment shown in Fig. 1a was passed through a similar column, but at $37^{\circ} \mathrm{C}$. The resulting elution profile is shown in Figure 3. The leading edge of the protein sample was stripped of cortisol by dissociation into the gel, as shown by the lag in the appearance of the cortisol. The cortisol so removed from protein was retarded in the gel by molecular sieving, and overtaken by fresh sample. Dissociation continued until the concentration of unbound cortisol in the gel reached that of the in-

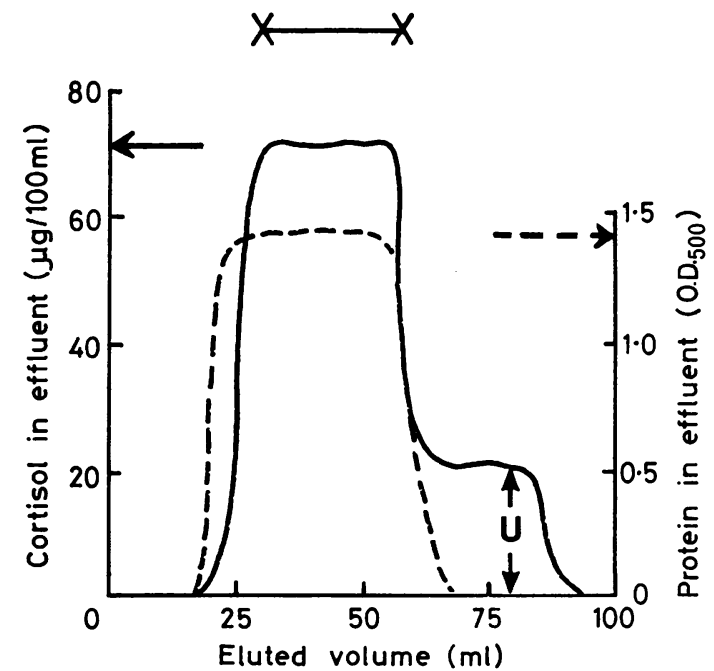

FIG. 3. Steady-state gel filtration of $42 \mathrm{ml}$ of same sample as in Fig. Ia on similar column but at $37^{\circ} \mathrm{C}$. Arrows against protein and cortisol scales indicate concentrations of each in the applied sample. $X-X$ and $U$ are explained in the text. 
coming sample. Sample entering after this passed through the column at equilibrium, maintaining its original cortisol and protein concentrations (as shown under the line marked $X-X$ in Figure 3). When the supply of sample ceased, the unbound cortisol in the column emerged as a second plateau of cortisol concentration (marked $U$ in Fig. 3), whose height is the equilibrium concentration of unbound cortisol. The difference in height of the two cortisol plateaux is the concentration of cortisol bound to all the proteins at $37^{\circ} \mathrm{C}$.

Since dissociation is prevented in the region $\mathrm{X}-\mathrm{X}$, which is a zone of constant composition in a steady state, the results share the independence of kinetic factors which is a feature of Gilbert's layering technique (Gilbert, 1966). They are also independent of sample size above the minimum needed to generate plateaux. In general, the minimum is a little less than twice the column void volume with Sephadex G-50, and on the $30 \times 1.4$ $\mathrm{cm}$ columns used identical results were obtained with samples larger than $25 \mathrm{ml}$.With smaller columns, as little as $10 \mathrm{ml}$ may be sufficient. In this way, steady-state gel filtration may be used to obtain accurate information about the concentration of protein-bound cortisol in plasma at high cortisol concentrations, while avoiding the uncertainties of the method of De Moor et al (1962). While the method cannot give the corticosteroid-binding globulin concentration from a single plasma measurement, neither does the method of De Moor et al as is shown above. But steady-state gel filtration does indicates the ability of a plasma to bind cortisol at $37^{\circ} \mathrm{C}$. Ino disease when the concentration of corticosteroid-등 binding globulin is high or low, the concentration of protein-bound cortisol is increased or decreased at an given cortisol concentration; and steady-state gelo filtration, by eliminating artefactual variables, should ${ }^{\text {s }}$ yield useful clinical information about cortiso $\vec{p}$ binding in disease.

I am very grateful to Dr C. L. Cope for both criticism and encouragement. This work was carried out in his laboratory during the tenure of a Medical Research N Council grant.

\section{REFERENCES}

Burke, C. W. (1969). Biochim. biophys. Acta (Amst.), 176, 403.

De Moor, P. Heirwegh, K. Heremans, J. F. and Declerck-R M. (1962). J. clin. Invest., 41, 816.

, Deckx, R., and Steeno, O. (1963). J. Endocr., 27, 355

-

Doe, R. P., Fernandez, R., and Seal, U. S. (1964). J. clin. Endocr $24,1029$.

Gilbert, G. A. (1966). Nature (Lond.), 212, 296.

Lowry, O. H., Rosebrough, N. J., Farr, A. L., and Randall, R. J. (1951). J. biol. Chem., 193, 265.

Matsui, N., and Plager, J. E. (1966). Endocrinology, 78, 1159.

Quincey, R. V., and Gray, C. H. (1963). J. Endocr., 26, 509.

Sandberg, A. A., Rosenthal, H., Schneider, S. L., and Slaunwhite, W. R. (1966). In Steroid Dynamics. Proceedings of the Sym-O posium held at Tokyo, 1965, edited by G. Pincus, T. Nakao and J. F. Tait, p. 1. Academic Press, New York and London.

Seal, U. S., and Doe, R. P. (1963). Endocrinology, 73, 371

Slaunwhite, W. R., Jr., Lockie, G. N., Back, N., and Sandberg, A. A. (1962). Science, 135, 1062. 